Books, videos, CD-ROMs, DVDs and any other relevant items submitted for a review in the $B D J$ should be addressed to: Kate Maynard, Assistant Editor, British Dental Journal, NPG, 4-6 Crinan Street, London N1 9XW

\section{Key topics in human diseases for dental students}

\author{
P. Sooriakumaran, C. Jayasena, C. Scully \\ UK: Taylor \& Francis \\ price €25, pp 251 \\ ISBN 1841844357
}

The teaching of human disease to dental students is an aspect of the undergraduate curriculum that varies considerably in style and content between dental schools within the UK. The General Dental Council document The first five years is relatively vague about what should be addressed in human disease but it does recommend that it should cover aspects of medicine, surgery, pathology, microbiology and therapeutics relevant to the practice of dentistry. It has generally been accepted that few texts have adequately encompassed this subject area, either in full or short-note style. However, the present book joins a number of recent publications that attempt to address this 'gap' in the dental literature.

The aim of the book is to provide the reader, specifically clinical dental students, with a broad understanding of the main medical and surgical conditions they may encounter in practice. The material, which includes 50 topic-based sections, is presented in alphabetical order starting with subjects such as acute abdominal pain, allergy and anaemia through to stroke, trauma and upper respiratory tract infections. Each topic has been allocated four or five pages to cover basic features of presentation, investigation or management. Five facts are provided at the end of each section along with an outline of any dental implications. The inclusion of a sporadic reference at the end of four of the sections is strange. These references include two 'in press' articles by one of the authors, of limited relevance to dental students, and a couple of papers from the British Thoracic Society. While there is a separate section that suggests some further reading at the end of the book, I think it would be more useful to include a small number of references to established textbooks or review articles at the end of each topic section. Such an addition would lead the interested reader to appropriate literature. The material does include sections on essential conditions that a dental student would be expected to know, such as anaphylaxis, bleeding tendency, endocarditis, HIV and neck swelling. However, some sections have less relevance, for example gallstones, hernias, prostate cancer and urinary tract infections.

As a final comment for the publishers, the print on the back cover of the book is almost impossible to read due to the small font size and choice of colour. Overall, this book provides a useful revision tool for undergraduate and postgraduate dental students.

M.A.O. Lewis

\section{Modern dental assisting (8th edition)}

\section{L. Bird, D. S. Robinson \\ UK: Elsevier \\ price £44.99, pp 1121 \\ ISBN 0721639070}

This is a very large book, 1,072 pages, and divided into 11 parts with two CD-Roms enclosed. One CD-Rom gives good visual presentation of clinical skills, by video, to help the dental assistant to perform techniques in the dental surgery. The second CD-Rom is for the tutor, to supplement the learning package through reinforcement of the topics learnt - using exercises, questions and quizzes.

The first section of the book details the history of dentistry from the Egyptians to modern day requirement of the profession. As the textbook is written mainly for the American market, you will notice that the roles of the Dental Assistant/Expanded Dental Assistant are slightly different from those currently available in the United Kingdom. It goes on to describe the dental ethics and the responsibilities of the dental team, which can be related to the working guidelines that are given by the GDC in this country.

The anatomy section of the book is well laid out with very clear descriptions and photographs. Some of the information is given in more detail than required for the National Examination or NVQ. In particular, the dental anatomy and tooth morphology section is very informative, which would help any dental nurse studying for the above examinations. There are critical thinking passages at the end of each session, which would be helpful for the revision of topics.

Oral health and nutrition again gives very detailed information, especially regarding the relation between dental caries and sugar intake, along with brushing techniques and supplementary cleaning aids, types of toothpastes and mouthwashes that are available. Most are available in this country.

The infection control section offers good advice on hand cleansing and use and handling of personal protective equipment. Good advice and practice is given regarding the cleaning process prior to sterilisation, and the result of sterilisation errors. Obviously the sterilisation guide should be read in conjunction with the current BDA advice sheet (A12), Infection control in dentistry, and HTM 20/10, as some points referred to are in the American guidelines and may differ slightly.

Medical emergencies that may occur in the surgery are covered, giving signs and symptoms for the nurse to watch for. CPR guidelines are given, but again these need to be read in conjunction with the latest guidelines from the Resuscitation Council.

The rest of the book is devoted to delivery of dental care to the patient; it covers dental instruments, showing enlarged pictures of instruments, and how and when they are used. It covers the different branches of dentistry and procedures that are carried and the instruments required.

The radiography section is detailed and would be of help to a nurse thinking of taking the post qualification in radiotherapy; included is a section listing and displaying the problems that can arise at the processing stage. 

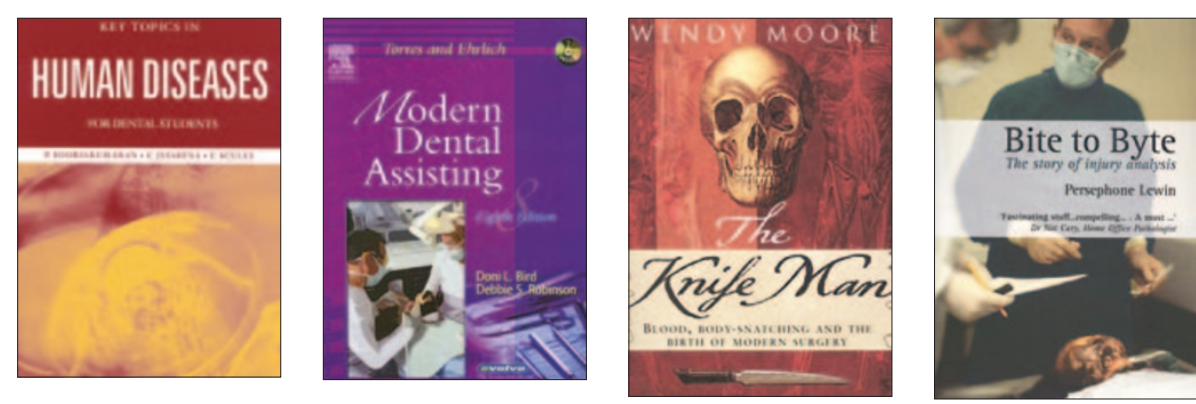

cannot recommend enough this scholarly, but vividly written biography.

A. R. Ogden good pictures. Composition
and their uses are given.

As someone who works with a large number of challenging patients with various special needs, I was not particularly comfortable with some of the terminology used for patients with learning difficulties/disabilities, but this is often particular to a country. Also, the methods of 'restraint' described would not be considered appropriate in this country.

On reflection, the textbook is informative and an ideal reference book which can be used alongside existing textbooks for the dental nurse, but it must be remembered that some of the chapters are aimed towards the American dental assistant, rather than the British dental nurse. I would use it with my group of dental nurse students working towards the National examination.

P. Boyt

\section{The knife man}

\section{W. Moore \\ UK: Bantam \\ price $€ 7.99$, pp 640 \\ ISBN 0553816187}

This is a stunning biography of John Hunter, the pioneering anatomist, surgeon and founder of scientific dentistry. Lurking behind a gruesome cover and a most inappropriate title, presumably designed to appeal on airport bookshelves, this gem of a book takes you straight back to the enthralling world of eighteenth century London. Chapter titles such as 'The Professor's testicle' and 'The Surgeon's penis' indicate the lively approach of the author and should appeal to students and junior staff.

There can seldom have been anyone as vibrantly alive as John Hunter. Surviving on only four hours' sleep every night (with an hour's nap in the afternoon), for much of his life he had a family and staff of more than 50 revolving around him. Yet he spent much of his time with the dead, both human and animal. Driven by profound curiosity about the mechanisms of life and free from deference to ancient texts, this self-taught young man from a small Scottish farm came to be a central figure and celebrity in London. Society lionised him and clamoured for personal consultations (or post-mortems on their loved ones, especially when money and property were involved).

There is a shocking and ghoulish side to this story, involving his dealings with body-snatchers; indeed this and his animal experiments led to his later being a role model for 'Dr Frankenstein' and 'Dr Jekyll and Mr Hyde'. However, fame and public curiosity enabled him to get away with much that would previously have offended. Almost single-handedly Hunter, the celebrity surgeon of his day, made postmortems acceptable to the upper classes, who would previously have been violently opposed to any interference with the remains of their relatives. Instead of death coming when the divine finger pointed at someone whose time was up, Hunter showed that death usually had a systemic cause. His immense knowledge of the comparative anatomy of creatures then being brought back from every corner of the globe, even led him to speculate that species developed from common ancestors, some 70 years before Darwin published The origin of species.

At the start of Hunter's career would-be surgeons needed only to demonstrate a good knowledge of Latin to enter the profession. This was so that they could repeat Roman and mediaeval operative techniques. Hunter's ideas were to change all of this. It was not enough to slavishly repeat the often-unsuccessful operations of the past. It was necessary to review and modify techniques in the light of experience. Hunter's influence and the Anatomy Act of 1832 were eventually to end the need for body-snatching and to stimulate professional medical and dental training.

With many of Hunter's specimens, preparations, papers and illustrations still being on view in the Hunterian Museum of the Royal College of Surgeons, London, I

\section{Bite to byte}

\section{P. Lewin \\ UK: Parrel Press \\ price $€ 14.99$, pp 370 \\ ISBN 0955042003}

This book is an interesting mix of case histories that help to map the progression of forensic dentistry into the realms of tool mark work - with a splash of humour from the author to lighten those darker moments.

It is not intended as a 'how to do' manual, but tracks the development of bite mark analysis from the subjective direct tracings of the biting edges of the teeth of a potential biter to the more objective, reliable and reproducible computergenerated overlays. It is then a short hop to adapt this technique to other patterned injuries. However, getting this evidence accepted in the courts proved to be an epic battle and required teamwork from David Lewin (forensic dentist and husband to the author) and Mrs Lewin.

It is also a personal look at some of the milestones encountered along the way by David Lewin and covers some of the most well known cases that he has assisted, including identifications in the Newall murders in Jersey and bites by politician Alan Clark's dog. Each case is carefully described and researched to give the reader fascinating insight into the unfolding case, complete with characters and court proceedings along with the relevance of the dental procedures. However, no dental degree or computer qualification is necessary to enjoy the book.

It is a most interesting read and is suitable for all those interested or involved in the forensic world - a mixture of scientific technique, forensic dental history, personal achievement and reflection. Although over 300 pages, it is definitely something to get your teeth into (sorry!). 